\title{
Effect of postpartum counseling on adoption of family planning within six months in women delivered in SSG Hospital: an interventional study
}

\author{
Sangita V. Patel ${ }^{1 *}$, Swapnil Malkhede', Maitri Shah², Latika Chugh', \\ Jesal H. Patel ${ }^{3}$, Ajay Parmar ${ }^{1}$
}

\author{
${ }^{1}$ Department of Community Medicine, ${ }^{2}$ Department of Obstetrics and Gynecology, Government Medical College, \\ Baroda, Gujarat, India \\ ${ }^{3}$ Department of Obstetrics and Gynecology, GCS Medical College, Ahmadabad, Gujarat, India
}

Received: 29 July 2021

Accepted: 01 September 2021

*Correspondence:

Dr. Sangita V. Patel,

E-mail: sangita_psm@yahoo.co.in

Copyright: (C) the author(s), publisher and licensee Medip Academy. This is an open-access article distributed under the terms of the Creative Commons Attribution Non-Commercial License, which permits unrestricted non-commercial use, distribution, and reproduction in any medium, provided the original work is properly cited.

\section{ABSTRACT}

Background: Increased family planning helps to reduce maternal mortality and infant mortality. Unmet need is spacing of birth for younger women and is the limitation of births for older women; both of which can be fulfilled by rigorous counseling. so the present study was conducted to measure the proportion of targeted women adopting family planning methods after postpartum counseling and to find out the type and timing of adoption.

Methods: A Non-randomized control trial was conducted. The study was carried out at the postpartum delivery ward of the obstetrics and gynecology department of SSG Hospital. 103 participants in the intervention group and 103 participants in the control group were interviewed.

Counseling and leaflet were given to the intervention group. The washout period was kept for one week. In the next week in the control group usual counseling was given by the counselor (standard of care). Second interview of the same participants was done telephonically or home visits after the 6 months to see the adoption of family planning method.

Results: Within six months of delivery, acceptance of contraceptive methods was more in intervention group $(72.85 \%)$ than in control group (48.52\%). Condom was the most common type of contraceptive intervention used in both interventional group (51.45\%) and control group (36.76\%) followed by Copper T use which was $14.21 \%$ in interventional group and $8.82 \%$ in control group. Majority of the women adopted contraceptives within two months of intervention.

Conclusions: Counseling may help in adoption of family planning methods among postpartum women.

Keywords: Family planning, Postpartum counseling, Contraceptive methods, Central Gujarat, Government hospital

\section{INTRODUCTION}

One of the important problems that developing countries like India are facing today is uncontrolled growth of population with the population size of 1.366 billion. ${ }^{1}$ Family planning is an important public health intervention with numerous potential health benefits for all women. One of those key benefits is the prevention of unintended pregnancies among women. Family planning helps people have the desired number of children, which as result improves the health of mothers and contributes to the nation's social and economic development. ${ }^{2}$ According to the annual report 2015-16, the current unmet need for family planning in India is 21.3 as per DLHS-III (2007-08). ${ }^{3}$ The immediate puerperium is an important period to initiate contraception. Women are often motivated to prevent or delay another pregnancy, they have immediate access to health care providers, and they are known not to be pregnant. ${ }^{4}$ The factors 
contributing to postpartum contraceptive use have been studied previously and include socio-demographic factors, prior experiences, obstetric care service utilization, and antenatal-postnatal education. The differences in the time and type of educational interventions have yielded diverse outcomes the postpartum period is a unique time to reach out to couples to initiate contraception. ${ }^{5}$ So the present study was conducted to measure the proportion of targeted women adopting family planning methods after postpartum counseling and to find out the factors affecting decision making in adoption of family planning method.

\section{METHODS}

The study was conducted in the postpartum delivery ward of the obstetrics and gynecology department of SSG Hospital from July 2016 to December 2017. We got data from the previous year from the obstetrics and gynecology department about adoption of family planning. We were expecting family method adoption in $50 \%$ of subjects in an interventional group and $28 \%$ in a control group. By keeping Alfa error at 5\% and by keeping power $80 \%$ the sample size becomes 74 in each group. By adding $20 \%$ loss to follow up the sample size becomes 94 in each group. Calculation of sample size was done using MedCalc version 20.008. Our loss to follow up was more than expected $(20 \%)$ which was near about $22 \%$ in both the groups. We have interviewed 94 participants in the intervention group and 94 participants in the control group at baseline. Due to loss to follow up we could interview 70 participants in the intervention group of which 19 were interviewed through home visit and the rest 51 were interviewed telephonically. Similarly, in the control group, we interviewed 68 participants, (with 26 loss to follow-up) out of which 15 were interviewed by home visit, and the rest 36 were interviewed telephonically. We interviewed all the subjects of both the groups in study to assess baseline understanding of the subject.

\section{Inclusion criteria}

Inclusion criteria for the study were: those willing to participate in the study were included; women delivered in SSG Hospital, those women who were permanent residents of Vadodara.

The non-randomization technique was used for allocation of subjects in any of the two groups, interventional and control. 103 participants in the intervention group and 103 participants in the control group were interviewed. Patients were selected from postpartum delivery ward, SSG Hospital, Baroda. In intervention group we have given the counseling to those patient delivered in a week then in next week we had kept washout period then next week in control group usual counseling were given by counselor from obstetrics and gynecology department then again we had kept one week as a washout period we did this until our sample size was not achieved. We selected non-randomization as our sampling technique and kept a washout period to avoid dilution of our counseling with the control group. The first interview was taken within 48 hours of delivery. The second interview of same participants was done telephonically or home visits after the 6 months. Information given by the patients was kept confidential. Counseling of each patient falling under an interventional group was done at one time during the participation in study. Preferably within 48 hours of delivery. Control group received usual counseling on contraceptive methods by the counselor in a group which was provided by obstetrics and gynecology department. In intervention group first counseling was done by the social worker in group of 3 or more, followed by individual counseling where with counseling their problem about contraceptive methods was solved, counseling was given in a language that is understood by the patient for 20 to 30 minutes. Components of counseling comprised general information about family planning methods and their advantages and disadvantages. The patient was first introduced to a video of about 10 minutes in her native language then the patient was allowed to discuss with the doctor for 7-15 minutes. At the end of the counseling, material on the family planning methods was provided to the patients in the form of leaflets. Data entry was done using strict check files in excel sheet and analyzed using MedCalc version 20.008. The proportion of family planning method adoption in intervention and among control group was calculated by Chi-square test. Relative risk was calculated to see the effect of postpartum counseling on the adoption of family planning methods.

\section{RESULTS}

In the study population mean age of intervention and control group were 24.86 \pm 4.01 and $25.57 \pm 4.85$ respectively. The difference was statically insignificant. $60 \%$ of the participants in the intervention group were in the age group of 24-35 years while $55 \%$ of the participants in the control group were in the age group of 24-35 years.

The intervention group had $81(78.64 \%)$ and control group had $75(72.82 \%)$ Hindus and Study group had 22 $(21.36 \%)$ and control group had 28 (27.18\%) Muslims. None of the participants belonged to any other religion. $37(35.92 \%)$ had age between $15-18$ years at the time of marriage in study group and $24(23.53 \%)$ in control group. $66(64.7 \%$.) had age between 19-30 years at the time of marriage in study group and $78(76.47 \%)$ in control group. $7.77 \%$ of participants from the study group and $6.80 \%$ participants from control group were uneducated and $48.54 \%$ and $33.01 \%$ participants in study and control group respectively had completed primary schooling. $36.89 \%$ and $53.40 \%$ participants in the study and control group respectively had completed secondary or higher secondary schooling. $6.80 \%$ and $6.80 \%$ in study and control group were graduates. It shows the uniformity in the intervention group and control group. 
Proportion of family planning adoption in the intervention group and control group was $73 \%$ and $49 \%$ respectively. The difference was statically significant $(\mathrm{p}=0.005)$. The proportion of family planning adoption was 1.5 times more in the intervention group as compared with control group (relative risk 1.5). $33 \%$ family planning adoption in the intervention group was attributed due to postpartum counselling among intervention group (Table 1).

Table 1: Proportion of family planning method adoption in Intervention and among control group within six months of delivery.

\begin{tabular}{|llll|}
\hline \multicolumn{1}{|c|}{ Group } & $\begin{array}{l}\text { Adopted } \\
\mathbf{N}(\%)\end{array}$ & $\begin{array}{l}\text { Not Adopted } \\
\mathbf{N}(\%)\end{array}$ & Total \\
\hline $\begin{array}{l}\text { Intervention } \\
\text { group }\end{array}$ & $51(73)$ & $19(27)$ & 70 \\
\hline Control group & $33(49)$ & $35(51)$ & 68 \\
\hline Chi square test value $\mathbf{= 7 . 5 ;} \mathbf{p}=\mathbf{0 . 0 0 5}$ & \\
\hline
\end{tabular}

In the post-intervention group proportion of women using condoms consistently was $36(51.45 \%)$ and in control group post it was $25(36.76 \%)$. 5(7.14\%) in intervention group used female sterilization whereas, 2 (2.94) in control group used the same method. 10 (14.21\%) were using $\mathrm{Cu}-\mathrm{T}$ as a contraceptive method in intervention group and $6(8.82 \%)$ in control group. 19 (27.14\%)and 35 $(51.47 \%)$ in intervention group and control group respectively were not using any contraceptive method (Table 2).

Those who have adopted family planning method out of them $10(19.60 \%)$ women in intervention group and 4
(12.12\%) in control group adopted family planning method within $48 \mathrm{hr}$ of delivery. $19(37.25 \%)$ women in intervention group and 6 (18.18\%)in control group adopted family planning method within a month and 21 $(41.17 \%)$ women in intervention and $17(51.51 \%)$ in control group adopted family planning method within 2 month and 1 (1.96\%)of women in and $4(12.12 \%)$ in control group adopted family planning method within 3 month and $1(3.03 \%)$ in control group adopted family planning method within 4 month and 1 (3.03\%)of women in control group adopted family planning method within 5 months (Figure 1).

Table 2: Type of family planning method adoption in intervention and among control group.

\begin{tabular}{|lll|}
\hline $\begin{array}{l}\text { Type of } \\
\text { contraception }\end{array}$ & $\begin{array}{l}\text { Intervention } \\
\text { group } \\
(\mathbf{N}=70) ; \\
\text { frequency }(\%)\end{array}$ & $\begin{array}{l}\text { Control group } \\
(\mathbf{N}=68) ; \\
\text { frequency }(\%)\end{array}$ \\
\hline Condom & $36(51.45)$ & $25(36.76)$ \\
\hline Cu-T & $10(14.21)$ & $6(8.82)$ \\
\hline $\begin{array}{l}\text { Female } \\
\text { sterilization }\end{array}$ & $5(7.14)$ & $2(2.94)$ \\
\hline $\begin{array}{l}\text { Not using } \\
\text { anything }\end{array}$ & $19(27.14)$ & $35(51.47)$ \\
\hline
\end{tabular}

Out of 103 women 77 had never used any contraceptive method in pre intervention group. The reasons for not using any contraceptive methods in intervention group is shown in (Figure 2). $15(19.48 \%)$ in pre intervention and $9(47 \%)$ in post intervention had not given any response.

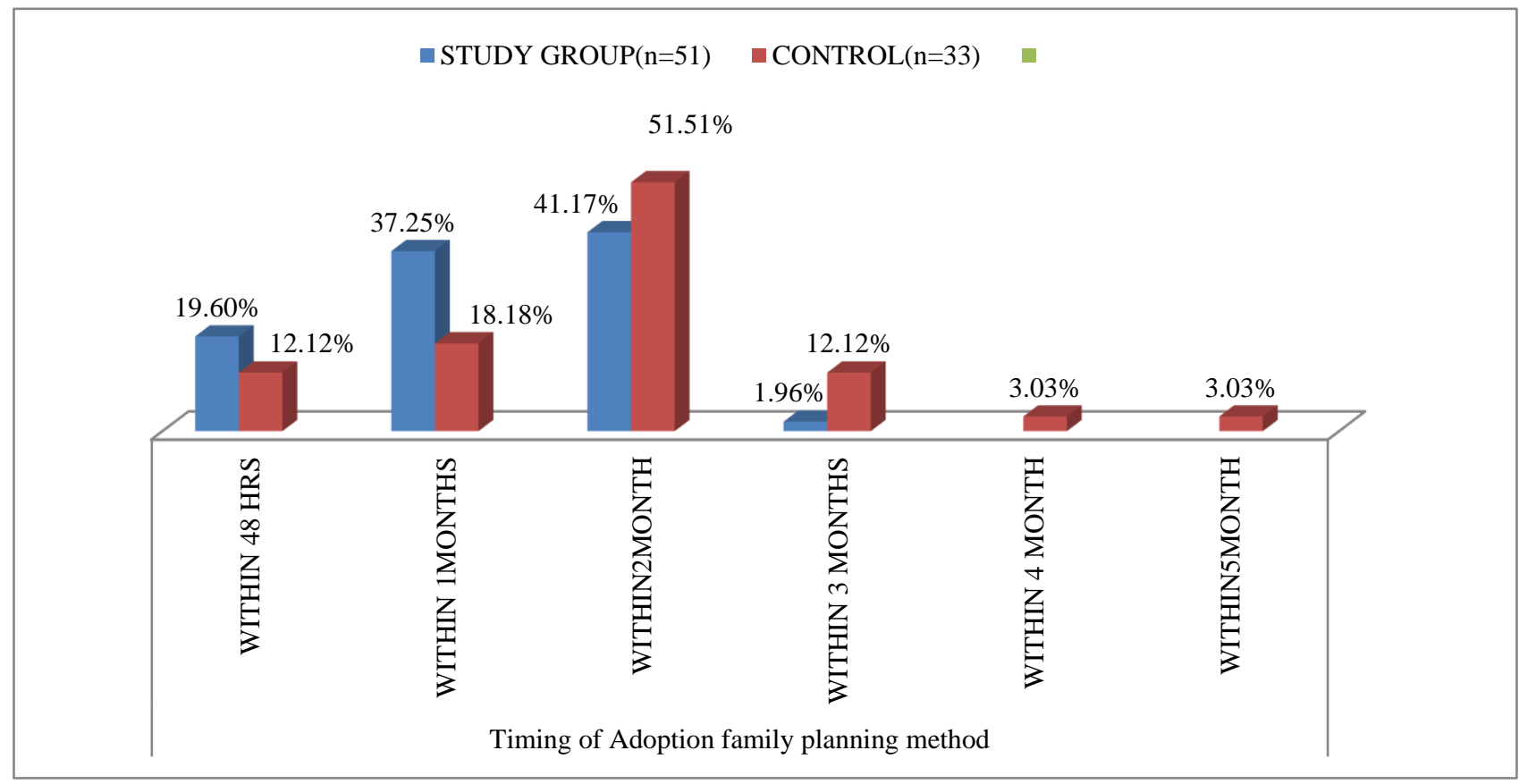

Figure 1: Timing of adoption of family planning method after delivery. 


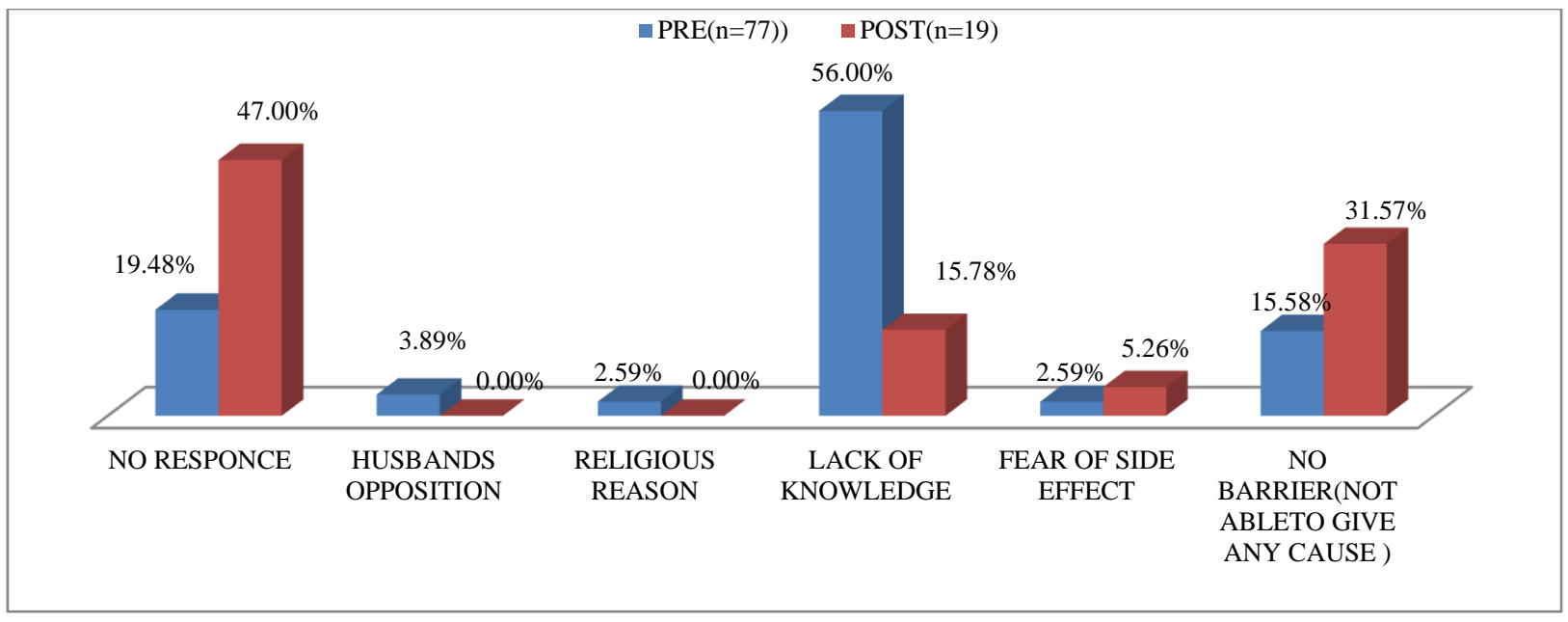

Figure 2: Reasons for not using contraception by women in the pre and post intervention group (Pre N=77, Post N=19).

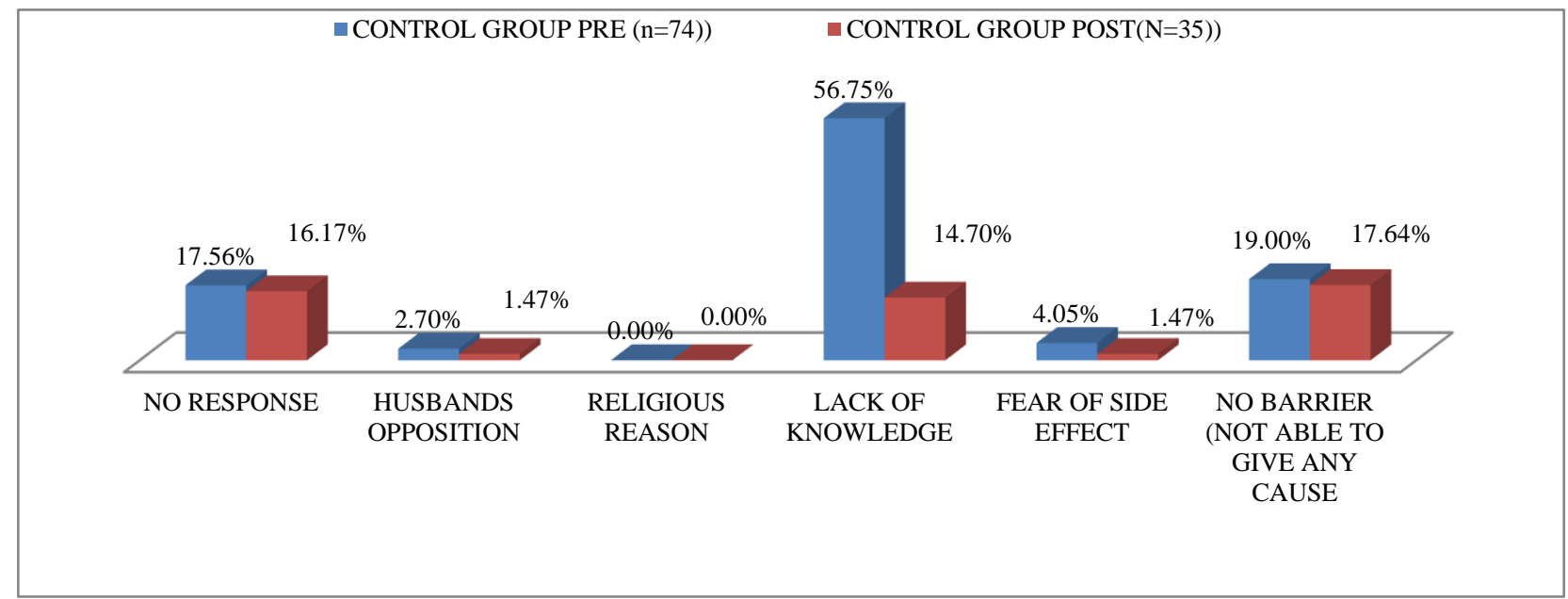

Figure 3: Reasons for not using contraception by women in the control group at pre $(\mathrm{N}=74)$ and post $(\mathrm{N}=35)$.

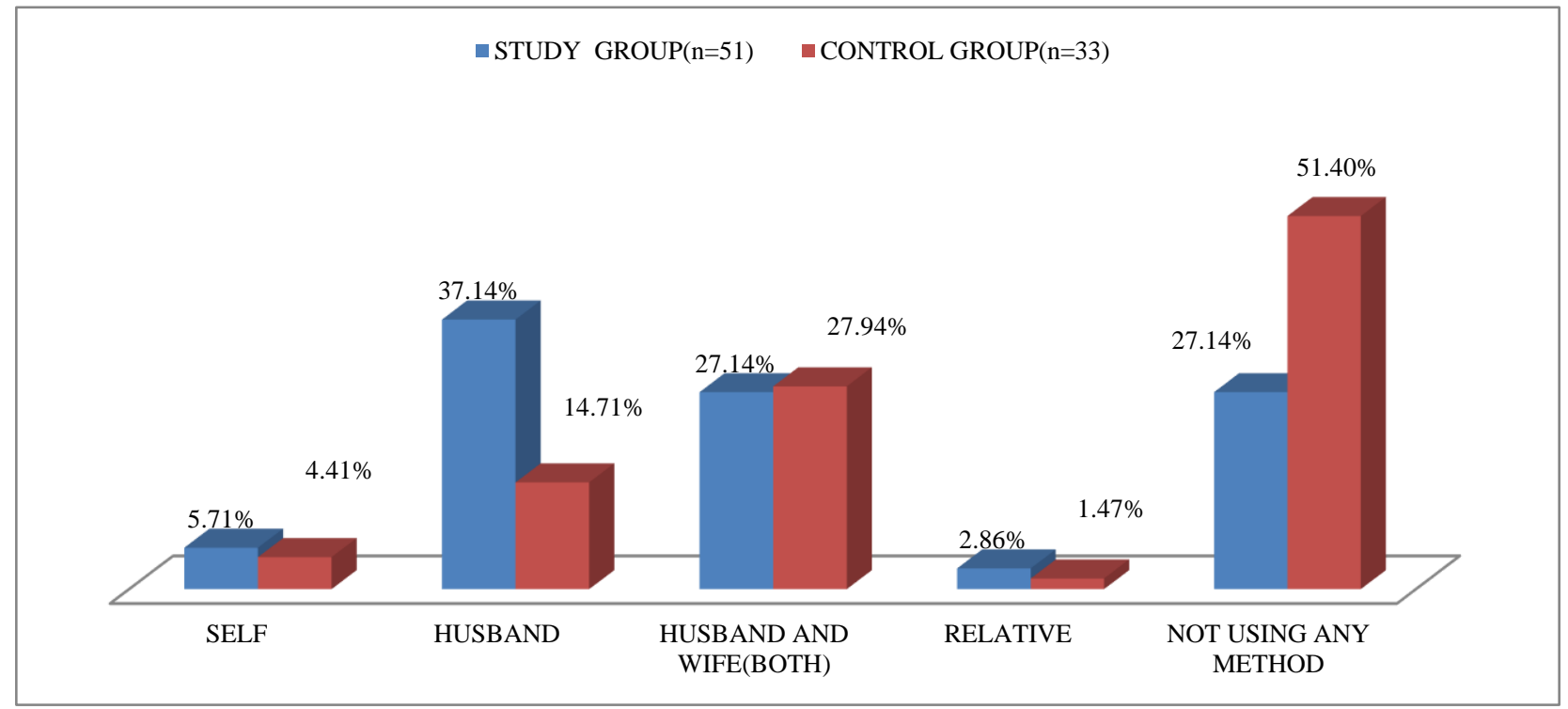

Figure 4: Distribution of person who helped in choosing family planning method among pre intervention and control group post. 
About 3 (3.89\%) had husbands' opposition in using family planning methods in pre intervention group. 43 (56\%) and $15.78 \%$ in pre and post intervention group did not have much knowledge about the use of contraceptives methods. $12(15.58 \%)$ and $6(31.57 \%)$ in intervention group before and after intervention not able to give any cause (Figure 2). Out of 103 women 74 had never used any contraceptive method in control group pre. The reasons for not using any contraceptive method, 13 $(17.56 \%)$ and $11(16.15 \%)$ in control group pre and post respectively had not given any response is depicted in (Figure 3 ). About $2(2.70 \%)$ in pre and $1(1.47 \%)$ in post had husband opposition in using family planning methods. No one in both pre and post control groups had religious opposition against using contraceptive method. $42(56.75 \%)$ and $10(14.70 \%)$ in pre and post control group respectively did not have much knowledge about the use of contraceptives methods. $14(19 \%)$ in control group pre and $12(17.64 \%)$ in control group post were not able to give any cause.

Husbands of $85(81.73 \%)$ women in pre intervention and $87(84.47 \%)$ women in control group in pre supported decision making about use of family planning method. After intervention, we noticed that husbands of 61 $(87.14 \%)$ women in intervention group and $61(89.71 \%)$ women of control group supporting in decision making about use of family planning methods (Figure 4). We also noticed that $11(61 \%)$ husbands in intervention group out of 18 who were not supporting in family planning decision started supporting in decision making. 9 (56\%) husbands in control group out of 16 who are not supporting in family planning decision started supporting in decision making.

In intervention group $4(5.71 \%)$ and in control group 3 $(4.41 \%)$ women have chosen family planning method by themselves as shown in (Figure 4). $26(37.14 \%)$ women in intervention group and $10(14.71 \%)$ in control group said that the method has been chosen by their husbands and $19(27.14 \%)$ in intervention group and $19(27.94 \%)$ in control group said that the method has been chosen by both husband and wife. In $2(2.86 \%)$ in intervention group and $1(1.47 \%)$ in control group relative helped in choosing family planning method. No one said that any friend had helped them in choosing family planning method. $19(27.145 \%)$ in intervention group and 35 $(51.40 \%)$ in control group were not using any family planning method. Mostly contraceptive method was chosen by husband and both husband and wife.

\section{DISCUSSION}

The postpartum period is a critical time to address high unmet family planning need and to reduce the risks of closely spaced pregnancies. The study carried out by Ram et al, stated that almost all ( $56 \%$ percent) had used just one method. Male condoms $(26 \%)$ were the most widely used method. ${ }^{6}$ Findings in our study are line with this study. The Similar study conducted by Vilmaze et al., showed that injectables alone account for nearly $20 \%$ of all the contraceptive, $24 \%$ account used condoms as a contraceptive method and $35 \%$ showed IUD as contraceptive method. ${ }^{7}$

One study done by Mengesha et al indicated that $1 \%$ majority of the women used a condom as contraceptive method and $9 \%$ of women used the injectable method and $3 \%$ used other. ${ }^{8}$ In a cross sectional study conducted by Bhardwaj et al $30.7 \%$ stated that using contraception was against their religion and $3(2.7 \%)$ had not given any response. ${ }^{9}$ In our study, patients stating use of contraceptives was against their religion was significantly less whereas those who did not respond were high. A cross sectional study carried out by Bhattathiry et al concluded that $15 \%$ had lack of knowledge $25 \%$ had fear of side effect, $11 \%$ had opposition from husband. ${ }^{10}$ Similarly across sectional study conducted by Patel et al among rural population of Vadodara Gujarat, India 2015 found that $55 \%$ of women had lack of knowledge, $25 \%$ lacked awareness. ${ }^{10}$

We have measured proportion of husbands supporting their wives in decision making for adoption of family planning methods in both, intervention and in control group and found that most of the husbands supported their wives. In the study conducted by Gebrekidan Mesfin et al in Tigray, Ethiopia $63.5 \%$ of women discussed family planning issues with their partners who were supportive in decision making. ${ }^{11}$ In our study, there was a significantly high support from partners in decision making about use of family planning method, even more so in post-intervention group which could be because of our counseling. Increased support was seen because couples had growing awareness for smaller family sizes and demand for family planning. Similar study carried out by Vouking et al in sab Saharan Africa $78 \%$ of men reported that decision was generally taken jointly with wife and believed that discussion on these issues should be always initiated in the family whereas, $9 \%$ of men had decided contraceptive method alone. ${ }^{12}$ Another similar study done by Adera et al in Ethiopia found that 91 percent of husbands were supporting in decision making. ${ }^{13}$ A similar study carried out by Thakor et al Gujarat using $79.7 \%$ of both women and husbands chose the contraceptive methods jointly. ${ }^{14}$ In our study $27 \%$ in intervention group and $28 \%$ in control group respectively chose type of contraceptive methods jointly. The difference in both studies may be due to $35 \%$ in intervention group and $15 \%$ in control group men decide type of contraceptive methods they used. This may due to most of the men in post-partum period using a condom as contraceptive method. The study conducted by Kumar et al in Haryana found that majority of the women adopted contraceptives within 3 months $(43.4 \%)$ and $(28.7 \%)$ in fourth month. ${ }^{15}$ In our study majority of results are in line with this. In current study, non-randomization technique was used for the allocation of subjects to control the contamination of the comparison group. It was the strength of our study. 


\section{Limitations}

Current study had several limitations that need to be highlighted. Our loss to follow up was $20 \%$ in the intervention group and control group because some of the enrolled women did not have access to telephones. Therefore, there is no effect on our result. As the sample was taken from a tertiary hospital, the results cannot be generalized. Mother-infant care integration programs take advantage of opportunities for contraceptive provision that may otherwise be missed. The limitations of the identified studies on mother-infant integration programs included unclear time and method of outcome measurement.

\section{CONCLUSION}

It was conclude that adoption of contraceptive methods in postpartum women increased, especially in the intervention group. Among those women who had adopted contraceptive methods most of them did it within a period of 2 months and the condom was chosen most commonly as a method of contraception by them.

\section{ACKNOWLEDGEMENTS}

Authors would like to thank Dr. V S Mazumdar; former HOD of community medicine department of medical college of Baroda for providing technical guidance.

Funding: No funding sources Conflict of interest: None declared

Ethical approval: The study was approved by the Institutional Ethics Committee

\section{REFERENCES}

1. World bank location. Available at: https://data.worldbank.org/indicator/SP.POP.TOTL?1 ocations=IN. Accessed on 20 May 2021.

2. Muttreja P, Singh S. Family planning in India: The way forward. Indian J Med Res. 2018;148(1):S1-9.

3. Family planning annual report 2014-15. Available at: http://www.nhm.gov.in/images/pdf/programmes/famil y-planing/annual-report/annual-report-fp-division2014-15.pdf. Accessed on 20 May 2021.

4. Cowman W, Hardy-Fairbanks A, Endres J, Stockdale CK. A select issue in the postpartum period: contraception the importance of providing postpartum contraception counseling. Proc Obstet Gynecol Proc Obs Gynecol. 2013;3315(1):105-9.

5. Lauria L, Donati S, Spinelli A, Bonciani M, Grandolfo ME. The effect of contraceptive counselling in the pre and post-natal period on contraceptive use at three months after delivery among Italian and immigrant women. Ann Super Sanita. 2014;50(1):54-61.

6. Ram F, Shekhar C, Chowdhury B. Use of traditional contraceptive methods in India \& its sociodemographic determinants. Indian J Med Res. 2014; 140(1):S17-28.

7. Yilmazel G, Balci E. Preferences and related factors for postpartum contraception in pregnant women. Iran J Reprod Med. 2013;11(10):801-6.

8. Mengesha ZB, Worku AG, Feleke SA. Contraceptive adoption in the extended postpartum period is low in Northwest Ethiopia. BMC Pregnancy Childbirth. 2015;15:160.

9. Kumar A, Bhardwaj P, Srivastava JP, Gupta P. A study on family planning practices and methods among women of urban slums of Lucknow city. Indian J Commun Health. 2011;23(2):75-7.

10. Bhattathiry MM, Ethirajan N. Unmet need for family planning among married women of reproductive age group in urban Tamil Nadu. J Family Community Med. 2014;21(1):53-7.

11. Mesfin G. The role of men in fertility and family planning program in Tigray Region. Ethiopian $\mathbf{J}$ Health Develop. 2002:247-55.

12. Vouking MZ, Evina CD, Tadenfok CN. Male involvement in family planning decision making in sub-Saharan Africa- what the evidence suggests. Pan Afr Med J. 2014;19:349.

13. Addis A, Tilahun B, Asefa G, Alganesh H, Woldegebriel G. Assessment of the role of men in family planning utilization at Edaga-Hamuse Town, Tigray, North Ethiopia,. Am J Nurs Sci. 2015;4(4): 174-81.

14. Thakor N, Prajapati D, Nayak S, Chauhan J. A cross sectional study on gender bias in fertility and family planning choices in a Rural area of Patan district of Gujarat, India. Int J Interdiscip Multidiscip Stud. 2014;1(7):77-84.

15. Kumar A, Bhardwaj P, Srivastava JP, Gupta P. A study on family planning practices and methods among women of urban slums of Lucknow city. Indian J Community Health. 2011;23(2):75-7.

16. Nibret MG, Simegn A, Dereje A, Gebrehana H, Getie A, Getnet B, et al. Postpartum modern contraceptive utilization and associated factors among women who gave birth in the last 12 months in Addis Zemen, South Gondar, Ethiopia: Community-Based CrossSectional Study. Int J Womens Health. 2020;12:124151.

Cite this article as: Patel SV, Malkhede S, Shah M, Chugh L, Patel JH, Parmar A. Effect of postpartum counseling on adoption of family planning within six months in women delivered in SSG Hospital: an interventional study. Int J Reprod Contracept Obstet Gynecol 2021;10:3864-9. 